\title{
The Different Contribution of Vocabulary Learning Strategies to Students with Varying Vocabulary Size
}

\author{
Supika Nirattisai (Corresponding author) \\ Department of Languages and Linguistics, Faculty of Liberal Arts \\ Prince of Songkla University, Hat Yai Campus, Songkla, Thailand \\ E-mail: supika_mew@hotmail.com \\ Thanyapa Chiramanee
}

Assoc. Prof. Dr., Department of Languages and Linguistics, Faculty of Liberal Arts

Prince of Songkla University, Hat Yai Campus, Songkla, Thailand

E-mail: thanyapa.c@psu.ac.th

Received: August 6, 2014 Accepted: Sep. 11, $2014 \quad$ Published: November 1, 2014

doi:10.5296/jse.v4i4.6196

URL: http://dx.doi.org/10.5296/jse.v4i4.6196

\begin{abstract}
The objective of this study was to investigate the contribution of vocabulary learning strategies to the vocabulary size of high and low vocabulary students. To achieve this aim, the relationship between vocabulary learning strategies used by the high and low vocabulary students and their vocabulary size were examined. Two hundred fifty-seven Prince of Songkla University undergraduates, majoring in 6 fields of study, namely, medicine, dentistry, nursing, engineering, accounting, and hospitality and tourism, were the subjects of this research, because of the upcoming establishment of the ASEAN Economic Community (AEC) in 2015 and the effect it would have on their future careers. Data collection for this target group included a questionnaire on vocabulary learning strategies, a bilingual English-Thai version of the test for vocabulary size, and a semi-structured interview. The results showed that the strategies for vocabulary development were highly connected to vocabulary size of both high and low vocabulary subjects. Among 39 vocabulary learning strategies, 18 strategies had a significant correlation with the vocabulary size of the high vocabulary subjects and 13 strategies were significantly correlated with the vocabulary size of the low vocabulary subjects. There were 8 vocabulary learning strategies which had a significant correlation with the vocabulary size of both groups.
\end{abstract}

Keywords: Vocabulary learning strategies, Contribution, Vocabulary size 


\section{Introduction}

As a consequence of the formation of the ASEAN Economic Community in 2015, Thais will find that English will become ever more significant in their lives, especially in terms of work prospects. The EF English Proficiency Index (EF EPI, 2013) stated that the English proficiency of Thai people is found to be at "a very low proficiency level" and it is lower than people in many ASEAN countries such as Vietnam, Indonesia, Malaysia. Therefore, to profit from ASEAN and its open goods exchange economy, Thais will have to have a certain level of English proficiency.

Vocabulary knowledge plays an essential role in developing students' language abilities (Nation, 1993). In studies by McCarthy (1990 \& 1998) and Waring and Nation (1997), they showed that learners should have an extensive vocabulary range to be able to communicate; small vocabulary size is a barrier to learners' language development. Many studies revealed that the lack of vocabulary knowledge affects L2 learners, including Thais, negatively, in all aspects of their use of language (Sawangwarorose, 1984; Olmos, 2009; Sukkrong, 2010).

Vocabulary learning strategies are an excellent approach to extend the word range of learners. Nation (2001) asserts that learners can retain rich vocabulary by the help of vocabulary learning strategies. According to Cunningworth (1995), this method is a powerful way of assisting students, its main advantage being that learning these strategies helps students become responsible for their own learning (Scharle \& Szabo, 2000; Nation, 2001). Gairns and Redman (1986) pointed out how important students' independent vocabulary acquisition is. Why this is important is because teachers cannot be responsible for selecting all words that students need to know after their elementary level so the students have to take control of their own learning. Sokmen (1997) reinforced this idea by stating that as learners cannot be expected to remember all the vocabulary they need in class, so this responsibility for their own increasingly large vocabulary acquisition is vital.

Much research in the field of vocabulary learning reveals that particular vocabulary learning strategies are more effective than others in developing some learners (Sanaoui, 1995; Stoffer, 1995; Schmitt, 1997 as cited in Siriwan, 2007). In other words, the choice of use of vocabulary learning strategies can make learners achieve more and others less in vocabulary learning. Therefore, it is worthwhile to study vocabulary learning strategies which are more effective and appropriate for particular groups of students: high and low vocabulary students. In order to investigate the contribution of vocabulary learning strategies to the high and low vocabulary students, the relationships between their vocabulary learning strategies and their vocabulary size were investigated.

\section{Literature Review}

\subsection{Definition of Vocabulary Knowledge}

The definitions of vocabulary learning strategies have been proposed by many researchers. For O'Malley and Chamot (1990), vocabulary learning strategies are "the special thoughts or behaviors that individuals use to help them comprehend, learn, or retain new information" ( $p$. 1). Cameron (2001) describes vocabulary learning strategies as "the actions that learners take 
to help themselves understand and remember vocabulary items" (p. 92). Intaraprasert (2004) defines vocabulary learning strategies as "any set of techniques or learning behaviors, which language learners reported using in order to discover the meaning of new word, to retain the knowledge of newly-learned words, and to expand one's knowledge of vocabulary" (p. 53).

\subsection{Classification of Vocabulary Knowledge}

Schmitt (1997) proposed one of the better known and acceptable classifications of vocabulary knowledge. He divided the strategies for vocabulary acquisition into 5 sub-categories, namely: 1) memory, in which a new word is connected with previously acquired knowledge; 2) cognitive, somewhat similar to memory, but focusing on manipulative mechanical process; 3 ) metacognitive, ways of learning and deciding how to plan, monitor and evaluate preferred methods of study; 4) determination, which covers an individual's efforts to independently ascertain word meanings; and 5) social, which involves interaction with others in order to learn new words.

\section{Research Questions}

1. Which vocabulary learning strategies contribute significantly to the vocabulary size of high vocabulary students?

2. Which vocabulary learning strategies contribute significantly to the vocabulary size of low vocabulary students?

3. In what ways are the high and low group similar in the relationships between the strategies they use and the size of their vocabulary?

\section{Methodology}

\subsection{Subjects}

Two hundred fifty-seven students, majoring in 6 fields of study, at Prince of Songkla University participated in this research, because their subjects were ones that would be affected by the establishment of the ASEAN Economic Community (AEC). Thirty-nine of the participants studied medicine, 29 dentistry, 48 nursing, 90 engineering, 25 accounting, and 26 hospitality and tourism.

\subsection{Research Instruments}

\subsubsection{Vocabulary Learning Strategy Questionnaire}

The aim of the vocabulary learning strategy questionnaire, written in Thai, was to investigate the subjects' use of vocabulary learning strategies. This questionnaire was adapted from Schmitt's (1997) and Siriwan's (2007) questionnaires. The reliability of the questionnaire used in this present study was .92. The questionnaire consisted of 39 vocabulary learning strategies divided into five strategy categories: 11 were memory strategies, 5 were cognitive, 9 were metacognitive, 7 were determination, and 7 were social. 0 (never) - 5(always) were the gradations of the rating scales. 


\subsubsection{Vocabulary Size Test: Bilingual English-Thai Version}

A multiple choice test with 140 items and consisting of 10 items from each of 14th 1000 word-level was used for the English-Thai vocabulary size test. This was adapted from the monolingual English test given by Nation and Beglar (2007) and was used to determine the participants' vocabulary size. Each item has one target word with 5 options written in Thai. Below is an example from 4th 1000 word-level.

45. compost: We need some compost.
a. การสนับสนุนช่วยเหลืออย่างเต็มที่ (strong support)
b. ช่วยให้รู้สึกดีขึ้น (help to feel better)
c. วัสดุแข็งทำขึ้นจากหินและดินทรายผสมกัน (hard stuff made of stones and sand stuck together)
d. สิ่งที่เกิดจากการเน่าเปื่อยของพืช (rotted plant material)
e. ไม่ทราบคำตอบ (I don't know)

\subsubsection{Semi-Structured Interview}

The main objective of this semi-structured interview was to get in-depth information about the vocabulary learning strategy use of 8 randomly selected subjects from the high vocabulary group and 8 from the low vocabulary group. The subjects were also interviewed about their beliefs in the effectiveness of vocabulary learning strategies. The interview took about 15 minutes for each subject. The interview was recorded and the researcher took notes during the interview.

\subsection{Data Collection}

Two hundred fifty-seven subjects were asked to complete both the questionnaire on strategies for acquiring vocabulary and the vocabulary size test in English-Thai. According to Nation (2006), the vocabulary size of between 6000 and 9000 word families is considered a sufficient vocabulary size for receptive skills - reading and listening skills. Therefore, 6000 word families were taken as a level to divide the 257 subjects into 2 groups: high and low vocabulary subjects. There were 99 subjects in the high group and 158 subjects in the low group. Later, 8 randomly selected subjects from the high vocabulary group and 8 from the low vocabulary group were interviewed about their vocabulary learning strategy use and their beliefs in the effectiveness of vocabulary learning strategies.

\subsection{Data Analysis}

To identify the relationship between vocabulary learning strategies employed by the high and low vocabulary subjects and their vocabulary size, the Pearson correlation coefficient was calculated. 


\section{1) Macrothink}

\section{Results}

Table 1 shows the relationships between vocabulary learning strategies and the vocabulary size of 99 subjects in the high group and 158 subjects in the low group.

Table 1. Correlations between vocabulary learning strategies and vocabulary size

\begin{tabular}{lccc}
\hline \multirow{2}{*}{ Strategies } & High group $(\mathrm{N}=99)$ & & Low group $(\mathrm{N}=158)$ \\
\cline { 2 - 3 } memory & $\mathrm{r}$ & $.222^{*}$ & $\mathrm{r}$ \\
cognitive & $.246^{* *}$ & $.207^{* *}$ \\
metacognitive & $.263^{* *}$ & .097 \\
determination & $.272^{* *}$ & $.170^{*}$ \\
social & $.196^{*}$ & .133 \\
\hline overall & $.270^{* *}$ & $.203^{*}$ \\
\hline
\end{tabular}

** significant at the .01 level $*$ significant at the .05 level

In Table 1, the relationships between the overall vocabulary learning strategies and vocabulary size of both the high and low vocabulary groups were significant, $r=.270(p$ $<.01)$ for the high group, and $\mathrm{r}=.188(\mathrm{p}<.05)$ for the low group. This demonstrates that students with higher frequency of vocabulary learning strategy use possessed higher vocabulary size, indicating that the use of vocabulary learning strategies contributed significantly to their vocabulary size.

The high vocabulary subjects' use of all five categories: memory, cognitive, metacognitive, determination, and social was significantly correlated with their vocabulary size. The highest correlation with their vocabulary size was determination strategies, followed by metacognitive strategies, cognitive strategies, memory strategies, and social strategies, respectively.

The low vocabulary subjects' use of 3 strategy categories - memory, metacognitive, and social was significantly related to their vocabulary size; memory strategies had the highest correlation to their vocabulary size followed by social strategies and metacognitive strategies. Cognitive and determination strategies were not found to be significantly related to their vocabulary size.

The relationships between memory strategies and the vocabulary size of the high and low vocabulary subjects are presented in Table 2. 
Table 2. Correlations between memory strategies and vocabulary size

\begin{tabular}{|c|c|c|c|}
\hline \multirow[b]{2}{*}{ Items } & \multirow[b]{2}{*}{ Memory strategies } & \multicolumn{2}{|c|}{ Correlation (r) } \\
\hline & & $\begin{array}{l}\text { High group } \\
(\mathrm{N}=99)\end{array}$ & $\begin{array}{l}\text { Low group } \\
(\mathrm{N}=158)\end{array}$ \\
\hline 1 & study words with pictures & .051 & .150 \\
\hline 2 & make a group of words by topic for reviewing & .161 & .109 \\
\hline 3 & make a group of words by alphabetical order for reviewing & $.255^{* *}$ & .076 \\
\hline 4 & say words aloud when studying & .145 & .145 \\
\hline 5 & $\begin{array}{l}\text { stick the word and its meaning in a place where it can be } \\
\text { obviously seen }\end{array}$ & $.267^{* *}$ & $.186^{*}$ \\
\hline 6 & use words in sentences & .184 & .118 \\
\hline 7 & connect words to personal experiences & .109 & .074 \\
\hline 8 & learn words of an idiom together & .071 & .142 \\
\hline 9 & connect the word to its synonyms and antonyms & .186 & $.179^{*}$ \\
\hline 10 & associate the word with other words you have learned & .139 & $.199^{*}$ \\
\hline 11 & remember the word from its "root", "prefix", and "suffix" & $.215^{*}$ & $.289^{* *}$ \\
\hline
\end{tabular}

** significant at the .01 level * significant at the .05 level

As shown in Table 2, among 11 memory strategies, 3 strategies "make a group of words by alphabetical order for reviewing" (Item 3), "stick the word and its meaning in a place where it can be obviously seen" (Item 5), and "remember the word from its root, prefix, and suffix" (Item 11) were significantly correlated with the high vocabulary subjects' vocabulary size.

The low vocabulary subjects' use of 4 memory strategies was found to be significantly correlated with their vocabulary size. These strategies were "stick the word and its meaning in a place where it can be obviously seen" (Item 5), "connect the word to its synonyms and antonyms" (Item 9), "associate the word with other words you have learned" (Item 10), and "remember the word from its root, prefix, and suffix" (Item 11).

Interestingly, 2 strategies "stick the word and its meaning in a place where it can be obviously seen" (Item 5) and "remember the word from its root, prefix, and suffix" (Item 11) were significantly correlated with the vocabulary size of both groups.

The relationships between cognitive strategies and the vocabulary size of the high and low vocabulary subjects are shown in Table 3. 
Table 3. Correlations between cognitive strategies and vocabulary size

\begin{tabular}{clcc}
\hline \multirow{2}{*}{ Items } & \multicolumn{1}{c}{ Cognitive strategies } & \multicolumn{2}{c}{ Correlation (r) } \\
\cline { 3 - 4 } & & $\begin{array}{c}\text { High group } \\
(\mathrm{N}=99)\end{array}$ & $\begin{array}{c}\text { Low group } \\
(\mathrm{N}=158)\end{array}$ \\
\hline 12 & learn words through verbal repetition & .164 & .088 \\
13 & learn words through written repetition & .146 & .061 \\
14 & listen to a tape of word lists & .165 & .056 \\
15 & keep a vocabulary notebook wherever you go & $.291^{* *}$ & .084 \\
16 & use vocabulary flashcards & $.337^{* *}$ & $.202^{*}$ \\
\hline
\end{tabular}

** significant at the .01 level * significant at the .05 level

In Table 3, the high vocabulary subjects' use of 2 out of 5 cognitive strategies, "keep a vocabulary notebook wherever you go" (Item 15) and "use vocabulary flashcards" (Item 16) were significantly correlated with their vocabulary size.

The low vocabulary subjects' use of 1 cognitive strategy "use vocabulary flashcards" (Item 16) had a significant correlation with their vocabulary size. The only shared strategy among both groups was "use vocabulary flashcards".

Table 4 displays the relationships between metacognitive strategies and the vocabulary size of the high and low vocabulary subjects.

Table 4. Correlations between metacognitive strategies and vocabulary size

\begin{tabular}{|c|c|c|c|}
\hline \multirow[b]{2}{*}{ Items } & \multirow[b]{2}{*}{ Metacognitive strategies } & \multicolumn{2}{|c|}{ Correlation (r) } \\
\hline & & $\begin{array}{l}\text { High group } \\
\qquad(\mathrm{N}=99)\end{array}$ & $\begin{array}{l}\text { Low group } \\
(\mathrm{N}=158)\end{array}$ \\
\hline 17 & listen to English songs & $.202 *$ & .126 \\
\hline 18 & watch English television programs / English films & $.339 * *$ & .145 \\
\hline 19 & use English printed matter & $.217^{*}$ & $.266^{* *}$ \\
\hline 20 & use English websites & .052 & $.183^{*}$ \\
\hline 21 & test yourself with word tests & $.268 * *$ & .084 \\
\hline 22 & translate the meaning of words from English into Thai & $.260 * *$ & .118 \\
\hline 23 & translate the meaning of words from Thai into English & .146 & .052 \\
\hline 24 & play vocabulary games & $.228^{*}$ & .152 \\
\hline 25 & study words over time & .177 & .056 \\
\hline
\end{tabular}

** significant at the .01 level * significant at the .05 level

Table 4 shows significant correlations between 6 out of 9 metacognitive strategies and the high vocabulary subjects' vocabulary size. They were "listen to English songs" (Item 17), 
"watch English television programs / English films" (Item 18), "use English printed matter" (Item 19), "test yourself with word tests" (Item 21), "translate the meaning of words from English into Thai” (Item 24), and "play vocabulary games" (Item 24).

Two metacognitive strategies, "use English printed matter" (Item 19) and "use English websites" (Item 20) were correlated with the vocabulary size of the low vocabulary subjects.

Only metacognitive strategy "use English printed matter" (Item 19) revealed a significant correlation with the vocabulary size of both groups.

The findings on the relationships between determination strategies and the vocabulary size of high and low vocabulary subjects are presented in Table 5.

Table 5. Correlations between determination strategies and vocabulary size

\begin{tabular}{clcc} 
& & \multicolumn{1}{c}{ Determination strategies } & \multicolumn{2}{c}{ Correlation $(\mathrm{r})$} \\
\cline { 3 - 4 } Items & & High group & Low group \\
& & $\mathrm{N}=99)$ & $(\mathrm{N}=158)$ \\
\hline 26 & analyze parts of speech to guess the meanings of words & $.329^{* *}$ & $.158^{*}$ \\
27 & analyze affixes and roots to guess the meanings of words & $.271^{* *}$ & $.166^{*}$ \\
28 & guess the meanings of words from textual context & $.239^{*}$ & $.230^{* *}$ \\
29 & analyze any available pictures or gestures to understand the & .139 & .073 \\
30 & look up words in an English-English dictionary & $.221^{*}$ & .109 \\
31 & look up words in an English-Thai dictionary & .166 & .067 \\
32 & look up words in a Thai-English dictionary & -.053 & -.103 \\
\hline
\end{tabular}

** significant at the .01 level * significant at the .05 level

Four strategies and the vocabulary size of the high vocabulary subjects were significantly correlated. These were "analyze parts of speech to guess the meanings of words" (Item 26), "analyze affixes and roots to guess the meanings of words" (Item 27), "guess the meanings of words from textual context" (Item 28), and "look up words in an English-English dictionary" (Item 30).

Significant correlations were found between the low vocabulary subjects' use of 3 determination strategies and their vocabulary size. They were "analyze parts of speech to guess the meanings of words" (Item 26), "analyze affixes and roots to guess the meanings of words" (Item 27), and "guess the meanings of words from textual context" (Item 28).

It is interesting that 3 determination strategies "analyze parts of speech to guess the meanings of words" (Item 26), "analyze affixes and roots to guess the meanings of words" (Item 27), and "guess the meanings of words from textual context" (Item 28) showed a significant correlation with the vocabulary size of both groups.

Table 6 shows the correlations between social strategies and the vocabulary size of the high 
and low vocabulary subjects.

Table 6. Correlations between social strategies and vocabulary size

\begin{tabular}{|c|c|c|c|}
\hline \multirow[b]{2}{*}{ Items } & \multirow[b]{2}{*}{ Social strategies } & \multicolumn{2}{|c|}{ Correlation (r) } \\
\hline & & $\begin{array}{l}\text { High group } \\
\qquad(\mathrm{N}=99)\end{array}$ & $\begin{array}{l}\text { Low group } \\
(\mathrm{N}=158)\end{array}$ \\
\hline 33 & ask teachers to translate the meanings of words & .227 & .086 \\
\hline 34 & ask classmates to translate the meanings of words & .007 & $.341 * *$ \\
\hline 35 & ask other people to translate the meanings of words & .069 & $.210 * *$ \\
\hline 36 & discover new meanings through group work activities & $.217^{*}$ & .133 \\
\hline 37 & interact with classmates & .171 & .060 \\
\hline 38 & interact with English teachers & $.227 *$ & .086 \\
\hline 39 & interact with native English speakers & $.193 *$ & $.150^{*}$ \\
\hline
\end{tabular}

** significant at the .01 level * significant at the .05 level

Three of 7 social strategies "discover new meanings through group work activities" (Item 36), "interact with English teachers" (Item 38), and "interact with English native speakers" (Item 39) had a significant correlation with the vocabulary size of the high vocabulary subjects.

Three social strategies were significantly correlated with the vocabulary size of the low vocabulary size. These were "ask classmates to translate the meanings of words" (Item 34), "ask other people to translate the meanings of words" (Item 35), and "interact with English native speakers" (Item 39).

Only one social strategy "interact with English native speakers" (Item 39) was found to be significantly related to the vocabulary size of both groups.

In addition to the use of vocabulary learning strategy questionnaire, an interview was used to get further information about the use of two vocabulary learning strategies which had the highest correlation with the vocabulary size of the high and low vocabulary subjects: "watch English television programs / English films" and "ask classmates to translate the meanings of words", respectively. Eight high vocabulary subjects and eight low vocabulary subjects were interviewed.

The findings were that the high and low subjects employed the strategy "watch English television programs / English films" differently. Five from 8 high vocabulary subjects paid attention to unknown words appearing on TV or films and looked for their meanings, while only 2 low vocabulary subjects did.

Six out of 8 low vocabulary subjects believed that "ask classmates to translate the meanings of words" could help them learn new words, while only 2 high vocabulary subjects believed so.

\section{Conclusion and Discussion}


The findings of this present research are summarized and discussed as follows:

1. The relationships between the overall vocabulary learning strategies employed by the high and low vocabulary subjects and their vocabulary size were significant. For the high group, the use of determination strategies had the highest correlation with their vocabulary size with metacognitive, cognitive, memory, and social following with lower correlations. The low vocabulary subjects' use of memory strategies had the highest relation to their vocabulary size, followed by social strategies, metacognitive strategies, determination strategies, and cognitive strategies, respectively.

The findings that the overall vocabulary learning strategies were significantly correlated with the vocabulary size of both high and low vocabulary subjects are in line with the findings of several researchers (e.g., Gu \& Johnson, 1996; Waldvogel, 2011) determined that vocabulary size and the strategies used by high and low vocabulary subjects were positively related and that the use of the strategies affected the amount of vocabulary acquired by students in all groups; learners with a higher use of vocabulary learning strategies would acquire larger vocabulary size.

Determination strategies contributed the most to vocabulary acquisition of the high level learners, but there was no significant contribution to the vocabulary size of the low vocabulary subjects. This means that determination strategies did not seem to be very effective for the low vocabulary subjects in terms of vocabulary development. This may be due to their lack of sufficient vocabulary knowledge because determination strategies such as "analyze part of speech to guess the meaning of words", "analyze affixes and roots to guess the meaning of words", "guess the meaning from textual context", "look up words in an English-English dictionary" need an adequate knowledge of vocabulary to achieve them. Therefore, low use of determination strategies may have led to the lesser vocabulary size of the weaker group.

Memory strategies were found to be the highest contribution to the vocabulary size of the low vocabulary subjects and the third contribution to the high vocabulary subjects. In other words, memory strategies tended to be an effective strategy to develop the vocabulary size of both groups. This finding is in agreement with O'Malley et al. (1985) and Hulstijn (1997) who reported that Asian learners employ rote memorization strategies successfully in their learning vocabulary.

2. The study revealed interesting findings about vocabulary learning strategies. Among individual vocabulary learning strategies, 8 strategies significantly contributed to the vocabulary size of both high and low groups, 10 strategies to the high group only, 5 ones to the low group only, and 16 were not significantly related to the vocabulary size of both groups.

The findings about the significant contributions of 8 vocabulary learning strategies to the vocabulary size of both high and low vocabulary subjects would be beneficial to classroom teachers with mixed ability students. In many countries including Thailand, language teachers usually have students with mixed proficiency levels in a class; vocabulary learning strategies 
which could help all groups of learners acquire large vocabulary size would be an interesting one to use in this kind of classroom environment.

Fifteen strategies were found to be effective for a specific group of subjects - 10 strategies significantly contributed to the vocabulary size of the high vocabulary group only and 5 strategies significantly contributed to the vocabulary size of the low vocabulary group only. The strategy "watch English television programs / English films" had the highest contribution to the vocabulary size of the high subjects, but did not significantly contribute to the vocabulary size of the low subjects. The different contributions of this strategy may result from the low group's inappropriate use of this strategy. According to the interview, most high vocabulary subjects paid attention to unknown words appearing on television programs or movies and tried to work out their meanings while only 2 low vocabulary subjects reported doing this. This finding was supported by Chamot (1987) and Nation (2001) who found that many vocabulary learning strategies are misused by students and that effective learners are able to use vocabulary learning strategies appropriately while ineffective ones use them inappropriately.

The strategy "ask classmates to translate the meanings of words" had the most contribution to the vocabulary size of the low vocabulary subjects. However, no significant correlation was found between this strategy and the vocabulary size of the high subjects. The interview with the subjects revealed different beliefs between the high and low groups. The low vocabulary subjects tended to believe that this strategy could help them cope with unknown words while the high vocabulary subjects did not believe so. According to Schemmer (1990), learners' beliefs play a key role in learning achievement. Puchta (1999) also asserts that learners with supportive and positive beliefs tend to have motivation and frustration which lead them to overcome problems while learners with negative beliefs do not.

Overall, the findings of this present study suggest that language teacher should be aware of the importance of vocabulary learning strategies in enhancing students' vocabulary size and encourage students to frequently employ them. Helping students develop self-reliance would be one effective way to extend their strategy use, which would allow learners to become more independent in their vocabulary learning (Oxford \& Nyikos, 1989; Nation, 2001). Those learners with high self-reliance will have real control of their own learning and this level of control could lead them to high use of vocabulary learning strategies.

Moreover, individual vocabulary learning strategies were not found to be suitable for all types of learners. Some strategies are effective for high group only, some are for low group only, and some are effective for all student groups. Thus, it is important for teachers to know which vocabulary learning strategies provide a great benefit to the specific types of learners and introduce them to learners.

\section{Further studies}

This present study only investigated the relationships between vocabulary learning strategies and the vocabulary size of high and low vocabulary students. To further understand students' vocabulary learning strategies, more research should be conducted to study the frequency of 
vocabulary learning strategies used by high and low vocabulary learners to gain more insights into their vocabulary learning strategy use and their preferences for choices of vocabulary learning strategies.

\section{References}

Cameron, L. (2001). Teaching Language to Children. Cambridge: Cambridge University.

Chamot, A. U. (1987). The Learning Strategies of ESL Students. In A. Wenden \& J. Rubin (Eds.). Learner Strategies in Language Learning (pp. 71-84). Cambridge: Prentice-Hall.

Cunningsworth, A. (1995). Choosing your Course Book. Oxford: Heinemann.

EF English Proficiency Index (2013). Comparing English Skills between Countries - EF EPI. Retrieved February 20, 2014, from http:// www.ef,com/epi.

Gairns, R., \& Redman, S. (1986). Working with Words. CUP.

Gu, P. Y., \& Johnson, R. K. (1996). Vocabulary Learning Strategies and Language Learning $\begin{array}{llll}\text { Outcomes. Language } & \text { Learning, 46(4), }\end{array}$ http://dx.doi.org/10.1111/j.1467-1770.1996.tb01355.x

Hamzah, M., Kafipour, R., \& Abdullah,S.K. (2009). Vocabulary Learning Strategies of Iranian Undergraduate EFL Students and Its Relation to Their Vocabulary Size. European Journal of Social Science, 11, 39 - 50. http://dx.doi.org/10.5539/elt.v5n4p138

Hulstijn, J. H. (1997). Mnemonic Methods in Foreign Language Vocabulary Learning. In J. Coady \& T. Huckin (Eds.), Second Language Vocabulary Acquisition (pp. 203-224). Cambridge University Press: Cambridge.

Intaraprasert, C. (2004). ESE Students and Vocabulary Learning Strategies: A Preliminary Investigation (Unpublished doctoral dissertation). Suranaree University of Technology, Nakhon Ratchasima, Thailand.

McCarthy, M. (1990). Vocabulary. Oxford: Oxford University Press.

McCarthy, M. (1998). Vocabulary and Language Teaching. New York: Longman.

McComish, J. (1990). The Word Spider: A Technique for Academic Vocabulary Learning in Curriculum Area. Guideline, 12, 26-36.

Nation, P. (1993). Vocabulary Size, Growth and Use. In The Bilingual Lexicon. R. Schreuder and B. Weltens (eds.), Amsterdam/Philadelphia: John Benjamins, 115-134.

Nation, P. (2001). Learning Vocabulary in Another Language. Cambridge: Cambridge University Press.

Nation, P. (2006). How Large a Vocabulary is Needed for Reading and Listening? Canadian Modern Language Review, 63(1), 59-82. http://dx.doi.org/ 10.1353/cml.2006.0049.

Nation, P., \& Beglar, D. (2007). A Vocabulary Size Test. The Language Teacher, 31(7), 9-13. 


\section{Macrothink}

Journal of Studies in Education

ISSN 2162-6952

2014, Vol. 4, No. 4

Olmos, C. (2009). An Assessment of the Vocabulary Knowledge of Students in Final Year of Secondary Education. Is Their Vocabulary Extensive Enough? International Journal of English Studies, special issue, 73-90.

O’Malley, J. M., Chamot, A. U., Stewner - Manzanares, G., \& Russo, R. \& Kuper, I. (1985). Learning Strategy Applications with Students of English as a Second Language. TESOL Quarterly, 19, 285-296. http://dx.doi.org/10.2307/3586278

O' Malley, J. M., \& Chamot, A. V. (1990). Learning Strategies in Second Language Acquisition. New York: Cambridge University Press.

Oxford, R. (1990). Language Learning Strategies: What Every Teacher Should Know. Boston: Newbury House.

Oxford R., \& Nyikos, M. (1989). Variables Affecting Choice of Language Learning Strategies by University Students. The Modern Language Journal, 73, 291-300. http://dx.doi.org/10.1111/j.1540-4781.1989.tb06367.x

Puchta, P. R. (1999). Beyond Materials, Techniques, and Linguistic Analysis: The Role of Motivation, Beliefs, and Identity. Paper presented at the 33rd International IATEFL Annual Conference, Edinburgh.

Sanaoui, R. (1995). Adult learners' approaches to learning vocabulary in second language. The Modern Language Journal, 79(1), 15-28.

Sawangwaroros, B. (1984). American and British English. Phasa Parithat Journal, 4(2), 24-37.

Scharle, A., \& Szabo, A. (2000). Learner Autonomy: A Guide to Developing Learner Responsibility. Cambridge: Cambridge University Press.

Schommer, M. (1990). Effects of Beliefs about the Nature of Knowledge on Comprehension. $\begin{array}{llll}\text { Journal of } \quad \text { Educational } & \text { 8sychology, }\end{array}$ http://dx.doi.org/10.1037/0022-0663.82.3.498

Schmitt, N. (1997). Vocabulary Learning Strategies. In N. Schmitt, AND M. McCarthy, eds. Vocabulary: Description, Acquisition and Pedagogy (pp. 199-227). Cambridge University Press: Cambridge.

Siriwan, M. (2007). English Vocabulary Learning Strategies Employed by Rajabhat University Students (Unpublished Doctoral Dissertation). Suranaree University of Technology Nakhoratchasima, Thailand.

Sripetpun, W. (2000). The Influence of Vocabulary Size on Vocabulary Learning Strategies and Vocabulary Learning Strategies (Unpublished Doctoral Dissertation). Victoria: La Trobe University, Australia.

Sokmen, A. (1997). Current Trends in Teaching Second Language Vocabulary. In N. Schmitt \& M. McCarthy (eds.), Vocabulary: Description, Acquisition, and Pedagogy. Cambridge University Press. Spolsky, B. 1998. Sociolinguistics. Oxford University Press. 


\section{Macrothink}

Journal of Studies in Education

ISSN 2162-6952

2014, Vol. 4, No. 4

Stoffer, I. (1995). University Foreign Language Students' Choice of Vocabulary Learning Strategies as Related to Individual Difference Variables (Unpublished Doctoral Dissertation). The University of Alabama, USA.

Sukkong, J. (2010). Learning Achievement, Retention, and Attitudes Towards English Vocabulary Learning of Students Taught Games and Conventional Method (Unpublished master's thesis). Prince of Songkla University, Thailand.

Waldvogel, D. A. (2011). Vocabulary Learning Strategies among Adult Learners of Spanish as a Foreign Language (Unpublished Doctoral Dissertation). The University of Texas, Austin.

Waring, R., \& Nation, P. (1997). Vocabulary Size, Text Coverage, and Word Lists. In N. Schmitt and M. McCarthy (eds.) Vocabulary: Description, Acquisition and Pedagogy (pp. 6-19). Cambridge University Press: Cambridge.

\section{Copyright Disclaimer}

Copyright for this article is retained by the author(s), with first publication rights granted to the journal.

This is an open-access article distributed under the terms and conditions of the Creative Commons Attribution license (http://creativecommons.org/licenses/by/3.0/). 